\title{
FUZZY IDENTIFICATION OF THE RELIABILITY STATE OF THE MINE DETECTING SHIP PROPULSION SYSTEM
}

\author{
Michał Pająk ${ }^{1}$ \\ Łukasz Muślewski² \\ Bogdan Landowski \\ Andrzej Grządziela ${ }^{3}$ \\ ${ }^{1}$ University of Technology and Humanities, Radom, Poland \\ ${ }^{2}$ University of Science and Technology, Bydgoszcz, Poland \\ ${ }^{3}$ Polish Naval Academy, Poland
}

\begin{abstract}
The study presents the evaluation and comparative analysis of engine shaft line performance in maritime transport ships of the same type. During its operation, a technical system performs functions for which it was designed. It goes through different states. Dynamic state changes of a rotational system can be identified by means of its vibration measurement. For this purpose, a research was carried out which involved recording vibrations of the analysed rotational systems. The recordings were used for calculating selected characteristics in the time-domain, where one of the most unique is the value of the normalized mutual correlation function. On the basis of the concentration values, the characteristics which unambiguously determine the ability state were selected for further studies. Then an identification method for rotational system non-coaxiality was proposed. The method involves using fuzzy clustering. According to this method the values of input signal characteristics were used to formulate fuzzy clusters of system ability and inability states. The method can be used for identifying the current state of the system. The study presents the results of the application of this method in engine turbine shaft lines of minesweepers, with the rotational system selected as an example. It needs to be noted that the efficiency of identifying the operating state of the system with this method is higher than with other methods described in the literature by authors who deal with this issue. The research results have a significant impact on the evaluation of mechanical properties of the studied objects and directly affect operational states of mechanical systems, including those installed in minesweepers, thus determining their reliability.
\end{abstract}

Keywords: ships, rotational system, mutual correlation, non-coaxiality, fuzzy clusters

\section{INTRODUCTION}

Rotating machinery is widely used in energy transformation and power transmission industries. Malfunctioning of the rotational system is most commonly caused by the impact of external forces, fatigue corrosion, aging, and poor working conditions. This leads to unexpected downtime and economic losses. Therefore, monitoring the technical state of a machine system is becoming an important issue of the engineering and academic research. The vibration signal analysis based fault detection and rotor system diagnosis is one of the principal maintenance tools [17]. From the point of system operation damageability, reliability, and safety, vibrations are the primary diagnostic symptoms $[25,26,47,48,59]$.
Vibrations and noise generated by rotational subsystems occur, practically, in all mechanical systems of transport means including ships. Vibrations can be generated by shafts, axes and fans, depending on the type of transport means or device.

According to literature, it is possible to carry out the research on the basis of correlation analysis, and to identify early symptoms of rotational system dynamic changes, especially its misalignment, through measurement of its vibrations $[8,10-12,16]$. The Fourier transformation $[1,20]$ and the wavelet transformation $[37,38]$ have been widely applied in recognizing fault feature frequencies of machinery equipment. Wavelet packet decomposition is utilized to analyse acoustic emission of signals and thus to identify the failure of a tribological system [2]. It is also applied to 
provide temporal-frequency information and capture the energy features [5], and to denoise non-stationary signals [49]. Although the wavelet analysis is widely used in vibration signal processing, there are certain problems concerning its application, such as difficulties in finding the best threshold and selecting the proper wavelet basis.

Vibration signals of the rotating machinery can have nonlinear and non-stationary characteristics when the mechanical transmission system fails to operate properly. Empirical mode decomposition (EMD) has been proved to be the proper method for dealing with nonlinear and nonstationary signals. In this method, any complex information can be adaptively decomposed into a number of individual, mono-component signals described by intrinsic mode functions. However, EMD has some problems, such as endpoint effect or modal aliasing. To cope with EMD disadvantages its some extensions have been developed. One of them is ensemble EMD (EEMD) [44]. Ensemble empirical mode decomposition has many advantages and has been applied in many scientific fields $[50,52]$. Another extension of EMD is variational mode decomposition (VMD). Through adaptive quasi-orthogonal signal decomposition, VMD decomposes the multi-component signal into several single-component signals, thus solving the problem of mode aliasing of EMD. Simultaneously, VMD makes use of Wiener filtering and has good noise robustness [23].

The EMD method and its extensions are often used in hybrid solutions, where these methods are combined with other types of signal processing. Here, the HHT method can be considered as an example. This is an adaptive timefrequency signal processing method which was applied in the past to water wave analysis, EEG signal feature extraction, and vibration signal processing [40]. In [34], a method of extracting shock energy-associated features from the background of intense noise interference is proposed. The energy weighting method starts with raw vibration signal decomposition using EEMD and time-frequency mapping by Hilbert transformation. Subsequently, the time-frequency map is considered as a set of time series of energy values for each particular frequency and each signal, and is analysed to check if impulsive energy exists. Finally, each binary spectrum is converted into weights of particular energy compounds to total weight of energy, and a characteristic frequency corresponding to a specific fault is revealed.

For monitoring the condition of a rotor system when the vibration signals produce an impulsive signature, the Spectral Kurtosis (SK) method is used. [39, 46]. With this method, it is possible to extract a part of the signal with the highest level of impulsiveness. The SK method has been already applied successfully by many researchers in monitoring the condition of rotating machinery and fault diagnosing [45]. In [51], a new method combining the advantages of EEMD and SK for rotor bearing system multi-fault diagnosis is proposed.

As far as the rotor system multi-fault diagnosis is concerned, the faulty signal is often intermixed with vibrations or noise emitted by other sources $[22,56]$. A similar situation occurs in diagnosing the rotor system operation under transient conditions, when the vibration signal is affected by the speed change and the transmission path [21]. If the traditional Fast Fourier Transform is adopted, it will lead to frequency aliasing. Order Tracking (OT) is the most direct and effective method to deal with the fault diagnosis under variable conditions $[4,6]$. Non-stationary signals are converted into stationary signals by equal angle resampling. There are two types of OT: Hardware Order Tracking (HOT) and Computed Order Tracking (COT). The HOT performs equal angle sampling of the vibration signal with the analogue device [57]. The hardware devices are expensive and complex, which limits the range of application of this method. In the COT, the vibration signal and the key phase signal of the machine are collected synchronously in the equal time interval sampling mode. Then, the equal angle sampling sequence in the angle domain is obtained by the interpolation algorithm. COT has been applied to feature extraction and fault diagnosis of internal combustion engines [55]. In [14], a hybrid method based on order tracking, EEMD, and 1.5 dimension spectrum is proposed for extracting the rolling bearing fault feature, under variable conditions.

However, the feature frequency cannot always be detected due to difficulties in obtaining the value of rotating frequency or the values of operational parameters of mechanical parts, which limits its implementation. In such a case, the classification-based fault diagnosis is used as another method of vibration analysis to avoid calculation of fault feature frequencies. The classification methods which are frequently used in the field of fault diagnosis include linear discriminant analysis (LDA) [13], artificial neural network (ANN) [36], support vector machine (SVM) [58], and sparse representation based classification (SRC) [7].

LDA, as a basic Fisher discriminant classifier, pursues a low degree of coupling between classes and a high degree of polymerization within a class. ANN provides nonlinear mapping between symptoms and faults. SVM is a machine learning method based on the statistical learning theory, and produces a favourable generalization performance. The basic principle of SRC is to sparse code a test sample over a dictionary and then to perform the classification based on the reconstruction error. SRC and its variants have been widely applied in face recognition, EEG signal classification, and music genre classification, or to reduce the dimension of original vibration signals. In [53], on the basis of SRC, a classification method for machinery vibration signals, named Transform Domain Sparse Representationbased Classification (TDSRC), is proposed. In TDSRC, the dictionary for sparse representation is not constructed with raw samples, but with their transformation coefficients.

The authors also focused on vibration signal time-domain analysis. In works $[10,11,18,27]$, the best characteristics of vibration signals in terms of reliability state identification were selected. Subsequently, they were used to formulate the functional space in which the ability state and inability state clusters of signals were specified. Thanks to the proposed methods implementation, it was possible to correctly identify the ability state in $65 \%$ and the inability state in $94 \%$. Despite pretty high efficiency of the inability state identification, the 
study was performed in order to increase the ability state identification. As a result, a fuzzy classification of vibration signals in the time-domain was proposed. A detailed description of the method in presented in Chapter 4 . In order to facilitate understanding of the idea and to present its genesis, a short description of the performed operational tests (Chapter 2) and the elements of former works (Chapter 3) are also enclosed. The results of the method application in the considered naval vessels are discussed in Chapter 5. The paper is summed up by some conclusions formulated in Chapter 6 .

\section{OPERATIONAL TESTS OF MINE DETECTING SHIPS}

The study deals with selected types of ships, specifically with their propulsion systems. These ships are used by the Navy and their main task is to detect marine mines Fig. 1.

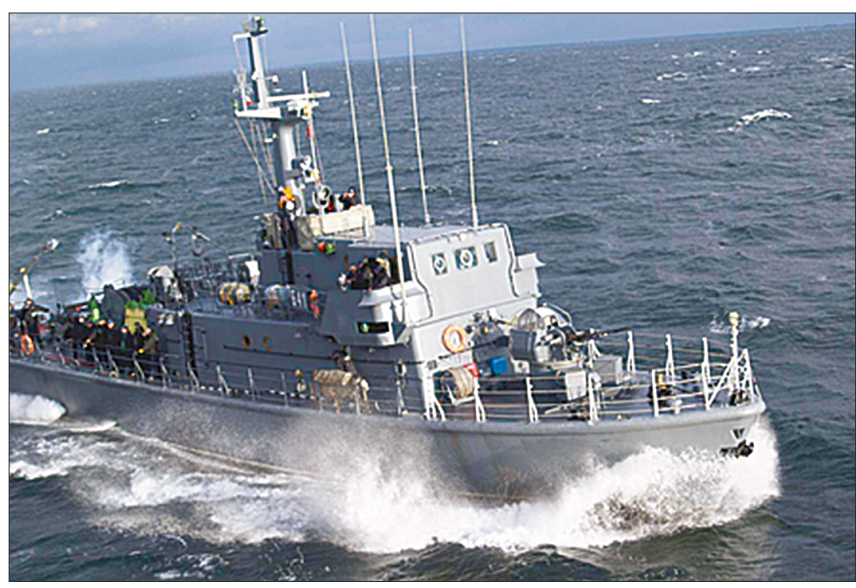

Fig. 1. Mine detecting ship $207 P$

Vibrations of the main engine shaft were recorded at 6 measuring points of the considered propeller systems. These points were located on: main engine bed plate, power consumer facing engine shaft end, hydrokinetic coupling, bearings at reversing reduction gear input and output, and thrust bearing, as shown in Fig. 2.

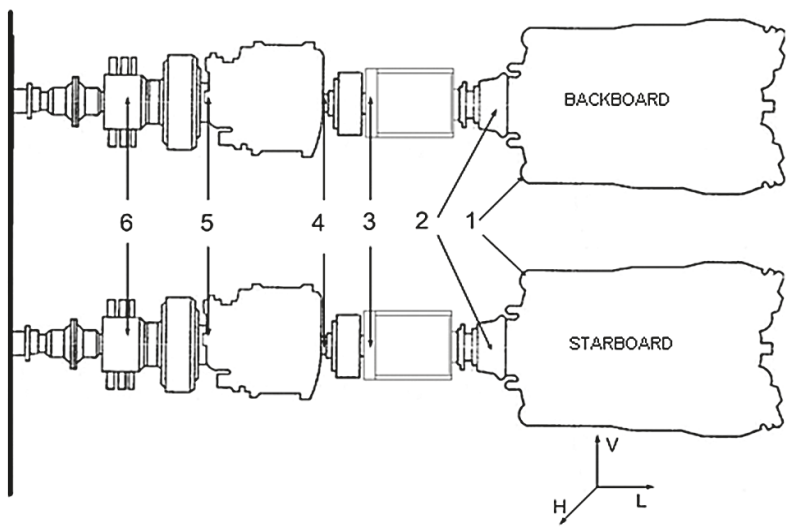

Fig. 2. Arrangement of measuring points on the analysed propulsion systems; 1-engine bed plate; 2-power consumer facing engine shaft end;

3-hydrokinetic coupling; 4-bearing at input of reversing reduction gear; 5-bearing at output of the gear; 6-thrust bearing
Each system is characterized by: nominal rotational speed equal to $1550 \mathrm{rpm}$, nominal power of $736 \mathrm{~kW}$, hydro-kinetic coupling with nominal slide $2 \%$ and skid control range $2-98 \%$, reversing reduction gear with coefficient 3.5:1, and thrust bearing (equipped with three ball bearings).

The vibration accelerations were recorded in four vessels: on two drive shaft lines in three vessels and on one shaft line in the remaining one. Six measurement points were situated on each shaft line. A sample vibration acceleration timehistory recorded during the measurement is shown in Fig. 3.

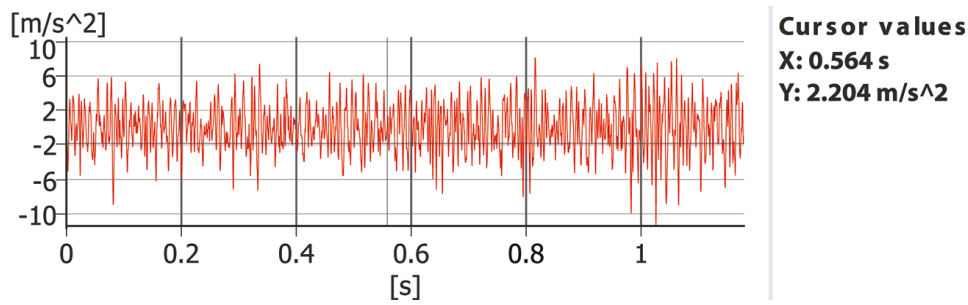

Fig. 3. Fragment of vibration acceleration time-history recorded during measurements

The operational tests were performed during normal ship operation when the wind did not exceed $2^{\circ} \mathrm{B}$, as otherwise, waves hitting the ship body would affect excessively the recorded vibrations. The temperature in the powerhouse compartment was nearly $40^{\circ} \mathrm{C}$. As already mentioned, the main engine shaft vibrations were measured at 6 points (for each drive shaft).

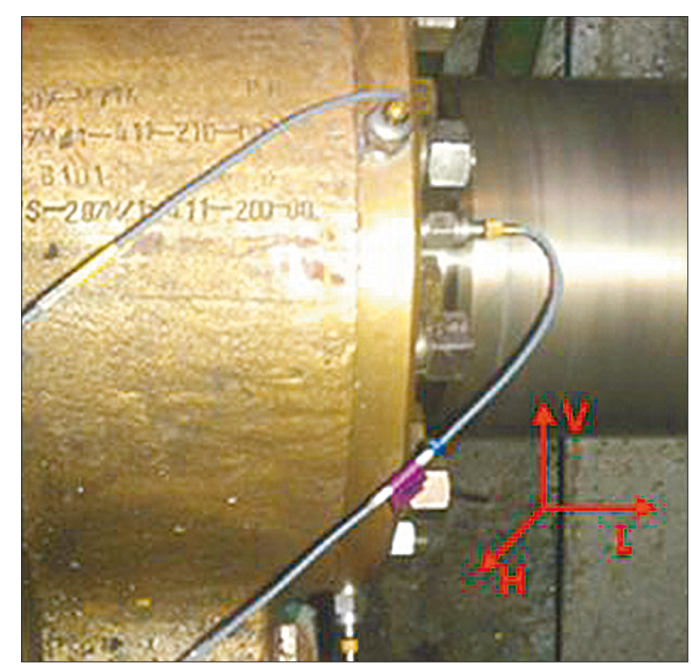

Fig. 4. Places on the resistance-carrier bearing where accelerometers were fixed, with marking of measurement directions

Three identical speedometers were used (B\&K 4514B) for this purpose. They were mounted on three mutually perpendicular axes. Since there was no possibility to use a threaded mutually perpendicular joint, converters were fixed with glue to the tested elements of the propulsion system.

After taking the measurements, the measurement paths were calibrated. All the recorded signals were synchronized by means of a four-channel gauge [3]. The vibration values were recorded within $3.2 \mathrm{kHz}$ band, at the sampling frequency equal to $8192 \mathrm{~Hz}$. 


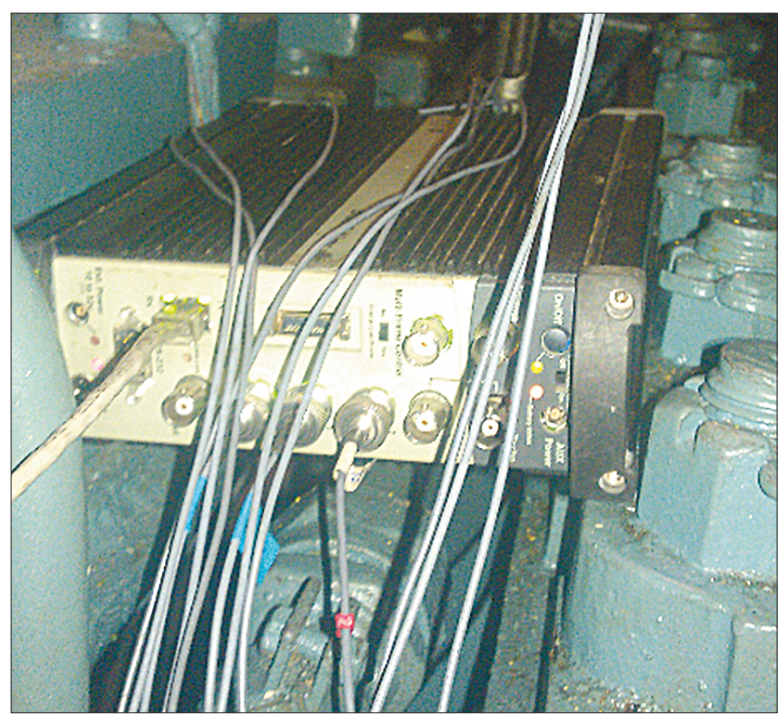

Fig. 5. Device used for measurements in B\&K 3560-B-120

Vibrations were recorded in three mutually perpendicular directions for 4 rotational speeds: $850 \mathrm{rpm}, 1100 \mathrm{rpm}, 1300 \mathrm{rpm}$, and $1500 \mathrm{rpm}$. The recorded results were stored in csv files. Each file included the vibration values for a given shaft system, measuring point, and rotational speed [11,27]. After recording, the files were divided into groups in such a way that each file in one group included 1024 measured values. However, after a preliminary analysis of the obtained files it turned out that the last file in each group contained only 1011 measurements. These files were excluded from further analysis. In this way, 252 files were obtained for shaft lines being in ability state, and 68 files for shaft lines being in inability state for each measurement point-vibration axis-rotational speed (PAS) combination. Each file contained the same number of measurements.

\section{VIBRATION SIGNAL TIME-DOMAIN ANALYSIS}

The time-histories of the recorded vibrations were treated as discrete signals expressed in the time domain. For each signal (vsi), the following characteristics $(\mathrm{CH}(v s i))$ were calculated [27, 41, 42]: integral, mean value, energy, average power (rms square), I order moment, II order moment, I order central moment, II order central moment, I order normalized moment, II order normalized moment, I order normalized central moment, II order normalized central moment, abscissa of the signal square gravity centre, the signal square variance, and the signal equivalent mean.

It was also established that the considered signals take non-zero values only within a finite interval, thus, they are impulse signals [59]. Having calculated the energy of signals according to Eq. (1), it was stated that these are impulse signals with limited energy [15]:

$$
E=\int_{t_{0}}^{t_{k}} v s^{2}(t) d t
$$

where $E$ is the energy of the signal time-history, $v s$ is the signal value, and $t_{0}$ and $t_{\mathrm{k}}$ are the times of interval beginning and end, respectively.

Thus, the signals can be considered as points of the $L^{2}\left(t_{0}, t_{\mathrm{k}}\right)$ function space, where time $t_{0}$ corresponds to the first measurement in the file and time $t \mathrm{k}$ to the last one. This space is a space of impulse signals with limited energy [42]. It is composed of a set of impulse signals with limited energy $V S$ and the metrics expressed by Eq. (2).

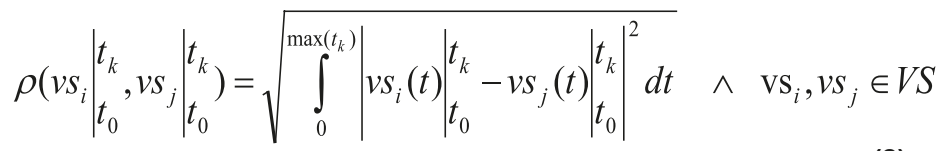

where

$$
\rho\left(v s_{i}\left|\begin{array}{l}
t_{k} \\
t_{0}
\end{array}, v s_{j}\right| \begin{array}{l}
t_{k} \\
t_{0}
\end{array}\right)
$$

is the functional such that $V S \times V S \rightarrow \mathfrak{R}^{+} \cup\{0\}, \max \left(t_{k}\right)$, $\max \left(t_{\mathrm{k}}\right)$ is the maximum time of the interval end, $v s_{i}$ is the time-history of $i$-th signal $i=1,2, \ldots, l v s, v s j$ is the timehistory of $j$-th signal $j=1,2, \ldots, l v s, l v s$ is the number of signal time-histories,

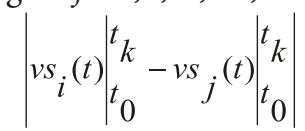

is the distance between the time-histories of $i$-th signal $j$-th signal, and VS is the set of signal time-histories.

Extension of the space with scalar addition, multiplication, and norm Eq. (3), constitutes the normalized linear Hilbert space [9]:

$$
\|v s\|_{L^{2}}=\sqrt{\int_{0}^{\max \left(t_{k}\right)}|v s(t)|^{2} d t}
$$

where is the norm of $L^{2}$ space.

The time-histories of vibration values are real signals. For such signals, the adjugated signal is equal to the primary signal. Thus, the normalized function of mutual correlation of the recorded vibration time-histories can be expressed as [10]

$\alpha_{v s_{i}, v s_{j}}^{\prime}(\tau)=\frac{\left(\left.\left.\int_{0}^{\max \left(t_{k}\right)} v s_{i}(t)\right|_{t_{0}} ^{t_{k}} \cdot v s_{j}(t-\tau)\right|_{t_{0}}{ }^{t_{k}} d t\right)^{2}}{\left.\left.\int_{0}^{\max \left(t_{k}\right)} v s_{i}(t)\right|_{t_{0}} ^{t_{k}^{2}} d t \cdot \int_{0}^{\max \left(t_{k}\right)} v s_{j}(t)\right|_{t_{0}} ^{t_{k}} d t}$

Above, the measure of signal similarity defines the distance in $L^{2}$ space between the time-histories depending on their relative shift along the time axis. The aim of the analysis of the recorded time-histories is to define a measure of their distance in space $L^{2}$. However, this measure should increase along with an increase in the distance of signals. For this reason, expression (5) was accepted as a measure of the distance [33].

$$
\delta\left(v s_{i}, v s_{j}\right)=1-\max \left(\alpha_{v s_{i}, v s_{j}}^{\prime}\left(\tau \in\left[-t_{k}, t_{k}\right]\right)\right)
$$


where $\delta\left(v s_{i}, v s_{j}\right)$ is the distance between signals $v s_{i}$ and $v s_{j}$ in space $L^{2}$, and $\alpha_{v s_{i}, v s_{j}}^{\prime}$ is the normalized mutual correlation function.

Randomly selecting one signal from each PAS subgroup to be the reference signal, the normalized mutual correlation function was calculated according to Eqs. $(4,5)$ as an additional characteristic of the recorded vibration time-histories.

According to the theory presented in [10], the characteristics were analysed in terms of concentration and unambiguity, using the following formulas:

$$
C H_{C O N} \Leftrightarrow \sigma_{C H(P A S)} \leq \overline{C H}(P A S) \cdot 0.15
$$

where $\mathrm{CH}_{C O N}$ is the concentrated characteristic, $\sigma_{C H(P A S)}$ is the standard deviation of the characteristic $\mathrm{CH}$, and $\overline{{ }_{\mathrm{CH}}(P A S)}$ is the mean value of the characteristic $\mathrm{CH}$ calculated from PAS group of signals.

$$
\begin{aligned}
& C_{U E} \Leftrightarrow\left\{C H \in C H_{C O N} \wedge\right. \\
& \left.\sigma_{C H\left(P A S_{I A}\right)}+\sigma_{C H\left(P A S_{A}\right)} \leq\left|\overline{C H}\left(P A S_{I A}\right)-\overline{C H}\left(P A S_{A}\right)\right|\right\}
\end{aligned}
$$

where $\mathrm{CH}_{U E}$ is the unambiguous characteristic, $\mathrm{CH}_{C O N}$ is the concentrated characteristic, $\sigma_{C H(P A S)}$ is the standard deviation of the characteristic $\mathrm{CH}$ calculated from $\mathrm{PAS}$ group of signals, $\overline{\mathrm{CH}}(P A S)$ is the mean value of the characteristic $\mathrm{CH}$ calculated from $P A S$ group of signals, $P A S_{I A}$ is the PAS group of signals recorded on rotational systems being in inability state, and $P A S_{A}$ is the $P A S$ group of signals recorded on rotational systems being in ability state.

The deviation from the mean value in Eq. (6) was equal to 0.15 . This value was obtained as a result of the studies conducted by the authors and described in detail in [10] and [27]. For this value, the highest efficiency of inability state identification was achieved.

Tab. 1. Results of concentration analysis of the normalized mutual signal correlation function

\begin{tabular}{|c|c|c|c|c|c|c|}
\hline $\begin{array}{c}\text { Measurement } \\
\text { point }\end{array}$ & 01 & 02 & 03 & 04 & 05 & 06 \\
\hline $\begin{array}{c}\text { PAS groups - ability } \\
\text { state }\end{array}$ & 12 & 12 & 12 & 8 & 12 & 12 \\
\hline $\begin{array}{c}\text { Concentrated PAS } \\
\text { groups - ability state }\end{array}$ & 10 & 11 & 12 & 8 & 10 & 10 \\
\hline $\begin{array}{c}\text { PAS groups - inability } \\
\text { state }\end{array}$ & 12 & 12 & 12 & 8 & 12 & 12 \\
\hline $\begin{array}{c}\text { Concentrated PAS } \\
\text { groups - inability state }\end{array}$ & 10 & 11 & 12 & 8 & 10 & 10 \\
\hline $\begin{array}{c}\text { Concentrated PAS } \\
\text { groups - total }\end{array}$ & $83 \%$ & $92 \%$ & $100 \%$ & $100 \%$ & $83 \%$ & $83 \%$ \\
\hline
\end{tabular}

The further analysis includes characteristics which meet the concentration and unambiguity condition to a relatively high degree. These were: signal energy, average power of signal, abscissa of the signal square gravity centre, signal square variance, and normalized mutual signal correlation function. In the case of the normalized mutual signal correlation function, an additional description should be made. Table 1 presents the results of the concentration analysis for the considered characteristic. It was established that the distance of signals, determined according to the value of the normalized mutual correlation function of the recorded vibration time-histories, meets the requirements of concentrated characteristics in more than $90 \%$ of the analysed cases. Therefore, despite the fact that the unambiguity condition is not fulfilled, this characteristic is also taken into further considerations.

\section{FUZZY CLASSIFICATION OF VIBRATION SIGNALS}

The selected characteristics determine a five-dimensional space, where each signal is expressed as a point and its coordinates are the values of the characteristics $[26,47,48]$. Detailed theoretical considerations about space formulation and industrial applications of the proposed approach can be found in the literature [28-32]. Although only concentrated and unambiguous characteristics were used as dimensions of the space of signals recorded during the industrial research, they form a cloud of points in space. In the cloud, regions of points related to the ability and inability states can be observed. In order to eliminate the problems arising from irregular and discontinuous distribution of the measured points in the space, elements of the theory of fuzzy sets are widely used $[33,35,54]$. Moreover, it was noticed that identification of regions is a similar issue to image recognition, where the fuzzy clustering implementation brings very good results $[19,24]$. Therefore, the regions were considered fuzzy clusters and identified according to the fuzzy c-means (FCM) method [35].

Having analysed the signals, it was found that the dimension ranges of the formulated space varied significantly. Therefore, prior to identification of clusters, the maximum and minimum values were calculated for each dimension and on this basis the values of coordinates of each signal were normalized according to Eq. (8):

$$
C H\left(v s_{i}\right)=\frac{C H\left(v s_{i}\right)}{\max (C H(V S))-\min (C H(V S))}
$$

where $V S$ is the set of vibration signals, $\max (\mathrm{CH}(\mathrm{VS}))$ and $\min (\mathrm{CH}(V S))$ are the maximum and minimum values of the characteristic $C H$ of $V S$, respectively, $v s_{i}$ is the vibration signal No. $i$, and $\mathrm{CH}\left(v s_{i}\right)$ is the value of the characteristic $\mathrm{CH}$ of the vibration signal $v s_{i}$.

Due to normalization of coordinates, each dimension in the space has the same impact on the clustering process. In the first step of identification, the signals were divided into two groups. The first group consisted of 17792 signals recorded on systems being in ability state and 2854 signals recorded on systems being in inability state. This group, referred to as the learning set, was used in the cluster identification process. The second group consisted of 5670 signals collected on rotational systems being in ability state and 1386 signals on systems being in inability state. This group, called the testing set, was used to examine the quality of the misalignment identification method. 
Next, the FCM method was performed using the learning set. This method requires three starting parameters to be set: the number of clusters (cno), the procedure termination condition parameter $(\varepsilon)$, and the cluster fuzzifier $(q)$, which is the parameter that controls how fuzzy the clusters will be. The higher it is, the fuzzier the clusters will be in the end. A large $q$ results in smaller membership values, and hence, fuzzier clusters. In the limit $q=1$, the memberships converge to 0 or 1 , which implies a crisp partitioning. In the beginning, initial random values of the membership matrix were generated. This matrix defines the membership degree of each signal to a given cluster. Then, central points of the clusters are calculated according to Eq. (9):

$$
c_{j, k}=\frac{\sum_{i=1}^{l v s} \mu_{i, j} \cdot C H_{k}\left(v s_{i}\right)}{\sum_{i=1}^{I} \mu_{i, j}}
$$

where $c_{j, k}$ is the k-th dimension of cluster No. $j, l v s$ is the number of signals $v s, \mu_{i, j}$ is the membership degree of $i$-th signal to cluster No. $j, \mathrm{CH}_{k}\left(v s_{i}\right)$ is the value of $k$-th characteristic of the vibration signal $v s_{i}$, and $v s_{i}$ is the vibration signal No. $i$.

Subsequently, the membership matrix values are recalculated according to formula Eq. (10):

$$
\mu_{i, j s}=\frac{1}{\sum_{j=1}^{c n o}\left[\frac{\sqrt{\sum_{k=1}^{c h n o}\left(c_{j s, k}-C H_{k}\left(v s_{i}\right)\right)^{2}}}{\sqrt{\sum_{k=1}^{c h n o}\left(c_{j, k}-C H_{k}\left(v s_{i}\right)\right)^{2}}}\right]^{\frac{2}{q-1}}}
$$

where $\mu_{i, j s}$ is the membership degree of $i$-th signal to cluster No. $j s$, cno is the number of clusters, chno is the number of dimensions, $q$ is the coefficient which defines the fuzziness of the cluster membership function, $c_{j k}$ is the $k$-th dimension of cluster No. $j, \mathrm{CH}_{k}\left(v s_{i}\right)$ is the value of $k$-th characteristic of the vibration signal $v s_{i}$, and $v s_{i}$ is the $i$-th vibration signal.

Calculations were performed until the termination condition, described by formula (11), was fulfilled:

$$
\sum_{j=1}^{c n o} \sum_{i=1}^{l v s}\left|\mu_{i, j}(t)-\mu_{i, j}(t-1)\right|<\varepsilon
$$

where $\mu_{i, j}$ is the membership degree of $i$-th signal to cluster No. $j, c n o$ is the number of clusters, lvs is the number of signals $v s$, $t$ is the iteration number, and $\varepsilon$ is the procedure termination condition parameter.

The termination condition parameter $\varepsilon$ can have a value between 0 and 1 . In the case of very complicated issues (coloured image processing) the used values range within $0.01-0.03$. However, applications of higher values can be found in the literature as well [43]. Therefore, in order to decrease the calculation time, $10 \%$ of the maximal value of the termination condition parameter was used in the conducted research.
Tab. 2. Parameters of the cluster identification process

\begin{tabular}{|c|c|c|c|}
\hline $\begin{array}{c}\text { Signals } \\
\text { collected } \\
\text { on systems: }\end{array}$ & $\begin{array}{c}\text { Number } \\
\text { of clusters } \\
\text { cno }\end{array}$ & $\begin{array}{c}\text { Fuzziness } \\
\text { coefficient } \\
\text { of the cluster } \\
\text { membership } \\
\text { function } q\end{array}$ & $\begin{array}{c}\text { Procedure } \\
\text { termination } \\
\text { condition } \\
\text { parameter } \varepsilon\end{array}$ \\
\hline $\begin{array}{c}\text { in ability } \\
\text { state }\end{array}$ & 2 & 3 & 0.1 \\
\hline $\begin{array}{c}\text { in inability } \\
\text { state }\end{array}$ & 2 & 2 & 0.1 \\
\hline
\end{tabular}

Tab. 3. Cardinality and coordinates of the identified clusters

\begin{tabular}{|c|c|c|}
\hline & Cardinality & Coordinates \\
\hline $\begin{array}{c}\text { Signals collected } \\
\text { on system in } \\
\text { ability state }\end{array}$ & 8084.79 & $0.068 ; 0.067 ; 0.479 ; 0.451 ; 0.934$ \\
\cline { 2 - 3 } & 9707.2 & $0.025 ; 0.024 ; 0.481 ; 0.457 ; 0.956$ \\
\hline $\begin{array}{c}\text { Signals collected } \\
\text { on rotational } \\
\text { systems in } \\
\text { inability state }\end{array}$ & 1026.88 & $0.176 ; 0.175 ; 0.484 ; 0.459 ; 0.979$ \\
\cline { 2 - 3 } & 1827.12 & $0.078 ; 0.077 ; 0.482 ; 0.458 ; 0.983$ \\
\hline
\end{tabular}

Identification of clusters was performed a few times during the tests, with the use of different values of cluster numbers and different fuzziness coefficients of the membership function, in order to define the noise of signals and their spatial arrangement. The identification process parameters were accepted only when the cardinality of the weakest detected cluster was not lower than $30 \%$ of the cardinality of the strongest one:

$$
\begin{aligned}
& \forall c_{j} \in C_{\text {ident }}: \operatorname{card}\left(c_{j}\right) \geq 0.3 \cdot \max \left(\operatorname{card}\left(C_{\text {ident }}\right)\right) \\
& \operatorname{card}\left(c_{j}\right)=\sum_{i=1}^{l v s} \mu_{i, j}
\end{aligned}
$$

where $c_{j}$ is the cluster No. $j, C_{\text {ident }}$ is the set of the identified clusters, $\operatorname{card}\left(c_{j}\right)$ is the cardinality of cluster No. $j, \max \left(\operatorname{card}\left(C_{i d e n t}\right)\right)$ is the maximum value of the cardinality among the clusters from set $C_{\text {ident }}, l v s$ is the number of signals $v s$, and $\mu_{i, j}$ is the membership degree of $i$-th signal to cluster No. $j$.

The values of starting parameters in the identification procedure are given in Table 2 . They were used in the process of cluster determination in the learning set of signals. The cardinality values and coordinates of the obtained clusters are presented in Table 3.

\section{IDENTIFICATION OF RELIABILITY STATES OF SHIPS}

Finally, one cluster was identified for each PAS subgroup from the test set of signals, according to the FCM method. The identification procedure was identical to that described in the previous section by Eqs. (9-11). To fulfil the requirement that the identification process should be independent from the data under consideration, the termination condition 
parameter $\varepsilon$ and the cluster fuzzifiers $q$ were equal to the values given in Table 2 . The number of clusters cno for each $P A S$ subgroup was set equal to one.

Next, the obtained clusters were analysed. The distance from the clusters identified for the set of signals collected on rotational systems being in ability state and the distance from the clusters identified for the set of signals collected on rotational systems being in inability state were calculated according to Eqs. $(13,14)$.

$$
d_{a s}\left(c t s t_{l s}\right)=\sum_{j=1}^{\text {cano }} \sqrt{\sum_{k=1}^{c h n o}\left(c a_{j, k}-c t s t_{l s, k}\right)^{2}}
$$

where $c t s t_{l s}$ is the cluster identified for the test set No. $l s$, das is the distance from clusters identified for signals collected on rotational systems in ability state, cano is the number of clusters identified for signals collected on rotational systems in ability state, chno is the number of dimensions, $c a_{j, k}$ is the $k$-th dimension of the ability state cluster No. $j$, and $c^{j, k} t_{j, k}$ is the $k$-th dimension of the test cluster No. $j$.

$$
d_{\text {ins }}\left(\operatorname{ctst}_{l s}\right)=\sum_{j=1}^{\text {cinno }} \sqrt{\sum_{k=1}^{\text {chno }}\left(\operatorname{cin}_{j, k}-c t s t_{l s, k}\right)^{2}}
$$

where $c t s t$ is the cluster identified for the test set No. $l s$, dins is the distance from clusters identified for signals collected on rotational systems in inability state, cinno is the number of clusters identified for signals collected on rotational systems in inability state, chno is the number of dimensions, $\operatorname{cin}_{j, k}$ is the $k$-th dimension of the inability state cluster No. $j$, and ctst $_{j k}$ is the $k$-th dimension of the test cluster No. $j$.

If the distance between the test cluster and the ability state clusters was larger than that between the test cluster and the inability state clusters, then the signals of the analysed test cluster were interpreted as signals of a rotational system being in inability state:

$$
d_{\text {as }}\left(\text { ctst }_{l s}\right)>d_{\text {ins }}\left(c t s t_{l s}\right)
$$

where $c t s t$ is the cluster identified for the test set No. $l s$, and $d_{\text {ins }}$ and $d_{a s}$ are the distances from clusters identified for signals collected on rotational systems in inability or ability state, respectively.

Otherwise, they were interpreted as signals of the rotational system being in ability state. Table 4 collates the results of the testing set analysis. The presented results indicate that the efficiency of the analysed method is higher for signals collected from rotational systems being in ability state rather than for those which are in inability state. Comparing the efficiency of the proposed method with earlier works by the authors [10, 11, 18, 27], it can be observed that the efficiency of ability state identification is slightly lower but still relatively high (higher than 90\%), whereas the efficiency of inability state identification is significantly higher. The overall efficiency of identification of rotational system non-coaxiality is higher than $82 \%$.
Tab. 4. Results of the testing set analysis

\begin{tabular}{|c|c|c|c|}
\hline $\begin{array}{c}\text { Signals } \\
\text { collected } \\
\text { on rotational } \\
\text { systems: }\end{array}$ & $\begin{array}{c}\text { Number } \\
\text { of signals } \\
\text { tested }\end{array}$ & $\begin{array}{c}\text { Number of signals } \\
\text { identified as } \\
\text { signals collected } \\
\text { on rotational } \\
\text { systems being } \\
\text { in ability state }\end{array}$ & $\begin{array}{c}\text { Number of signals } \\
\text { identified as } \\
\text { signals collected } \\
\text { on rotational } \\
\text { systems being } \\
\text { in inability state }\end{array}$ \\
\hline $\begin{array}{c}\text { in ability } \\
\text { state }\end{array}$ & 5670 & $4536(80 \%)$ & $1134(20 \%)$ \\
\hline $\begin{array}{c}\text { in inability } \\
\text { state }\end{array}$ & 1386 & $126(9 \%)$ & $1260(91 \%)$ \\
\hline
\end{tabular}

\section{CONCLUSIONS}

On the basis of the carried out tests it can be concluded that the distance of signals determined according to the normalized mutual correlation function and the recorded time-histories can be considered as a feature which unambiguously identifies the reliability state of a drive shaft line. The identification of rotational system non-coaxiality with the use of fuzzy clustering makes it possible to formulate a conclusion that the application of signal energy, signal mean power, abscissa of the signal square gravity centre, signal square variance, and normalized mutual signal correlation function for this purpose is justified, which has been proved by using the analysed method. Its efficiency is $80 \%$ for signals collected from rotational systems being in ability state, and $91 \%$ for systems being in inability state.

The novelty of the presented work involves developing a new vibration signal measurement method belonging to a relatively small group of methods which do not require fault feature frequency calculations. The method is a new approach to the considered issue, where the implementation of artificial intelligence techniques in the form of elements of the theory of fuzzy sets brings pretty high efficiency of ability state identification.

The proposed method can become a universal tool to be used for analysing propeller system vibrations. Nevertheless, further research in this area is planned. One of its directions will be analysing the influence of the cluster membership function shape on the efficiency of ability state identification.

Finally, it needs to be highlighted that mechanical properties of the propulsion system of a given vessel largely affect its operational state and, subsequently, the ability to perform reliable, timely, safe and efficient operational tasks.

\section{REFERENCES}

1. Antoni J.: Cyclic spectral analysis of rolling-element bearing signals: Facts and fictions. Journal of Sound and Vibration 2007 (304), pp. 497-529.

2. Bianchi D., Mayrhofer E., Groeschl M., Betz G., Vernes A.: Wavelet packet transform for detection of single events in acoustic emission signals. Mechanical Systems and Signal Processing 2015, Vol. 64-65, p. 441-451. 
3. Bielawski, P.: Diagnostics of marine propeller shafts. Journal of Polish CIMAC, 2011 Vol. 6 No. 2, pp. 31-40.

4. Borghesani P., Pennacchi P., Chatterton S., Ricci R.: The velocity synchronous discrete Fourier transform for order tracking in the field of rotating machinery. Mechanical Systems and Signal Processing 2014, 44, pp. 118-133.

5. Castejon C., Gomez M., Garcia-Prada J., Ordonez A., Rubio H.: Automatic Selection of the WPT Decomposition Level for Condition Monitoring of Rotor Elements Based on the Sensitivity Analysis of the Wavelet Energy. International Journal of Acoustic Vibration 2015, Vol. 20, Issue 2, pp. 95-100.

6. Coats M.D., Randall R.B.: Single and multi-stage phase demodulation based order-tracking. Mechanical Systems and Signal Processing 2014, 44, pp. 86-117.

7. Gang Tang, QinYang, Hua-Qing Wang, Gang-gang Luo, Jianwei Ma: Sparse classification of rotating machinery faults based on compressive sensing strategy. Mechatronics 2015, Volume 31, pp. 60-67.

8. Girtler J.: The semi-Markov model of the process of appearance of sea-going ship propulsion system ability and inability states in application to determining the reliability of these systems. Polish Maritime Research 4(80) 2013, Vol 20, pp. 18-24.

9. Górniewicz I., Roman S.: Mathematical Analysis for Physicians. Scientific. Publishing Office of Nicolaus Copernicus University of Torun, Torun 2000.

10. Grządziela A., Musiał J., Muślewski Ł., Pająk M.: A method for identification of non-coaxiality in engine shaft lines of a selected type of naval ships. Polish Maritime Research 2015, 1(85) Vol. 22, pp. 65-71.

11. Grządziela A. Muślewski Ł.: High quality simulation of the effects of underwater detonation impact. Journal of Vibroengineering, 2013, Issue 1, Volume 15.

12. Gurr C., Rulfs H.: Influence of transient operating conditions on propeller shaft bearings. Journal of Marine Engineering and Technology, No. 12/2008, pp. 3-7.

13. Haining Liu, Chengliang Liu, Yixiang Huang: Adaptive feature extraction using sparse coding for machinery fault diagnosis. Mechanical Systems and Signal Processing 2011, 25 pp. 558-574.

14. Hongkai Jiang, Qiushi Cai, Huiwei Zhao, Zhiyong Meng: Rolling bearing fault feature extraction under variable conditions using hybrid order tracking and EEMD. Journal of Vibroengineering 2016, Vol. 18, Issue 7, pp. 4449-4457.

15. Izydorczyk J., Pionka G., Tyma G.: Theory of Signals. Introduction. II corrected and completed edition. HELION, Gliwice 2006.
16. Kostek R., Landowski B., Muślewski Ł.: Simulation of rolling Bering vibration in diagnostics. Journal of Vibroengineering, 2015, Issue 8, Volume 17.

17. Lal M., Riwari R.: Multi-fault identification in simple rotor-bearing-coupling systems based on forced response measurements. Mechanism and Machine Theory 2012, Vol. 51, pp. 87-109.

18. Landowski B, Pająk M, Żółtowski B, Muślewski Ł.: Method of building a model of operational changes for the marine combustion engine describing the impact of the damages of this engine on the characteristics of its operation process. Polish Maritime Research, 2017 no 4 (96), vol. 24, pp. 67-76.

19. Leski J. M.: Fuzzy c-ordered-means clustering. Fuzzy Sets and Systems 2016, 286, pp. 114-133.

20. Li B., Mo-Yuen C., Yodyium T., et al.: Neural-network-based motor rolling bearing fault diagnosis. IEEE Transactions on industrial electronics, 2000, 47(5): pp. 1060-1069.

21. Lin J., Zhao M.: Dynamic signal analysis for speed-varying machinery: A review. Scientia Sinica 2015, Vol. 45, Issue 7, pp. 669.

22. Liu Z.W., Wei G., Hu J.H., Ma W.S.: A hybrid intelligent multi-fault detection method for rotating machinery based on RSGWPT. KPCA and Twin SCM 2017, Vol. 66, pp. 249-261.

23. Liu Y., Yang G., Li M., et al.: Variational mode decomposition denoising combined the detrended fluctuation analysis. Signal Processing 2016, Vol. 125, Issue C, pp. 349-364.

24. Miin-Shen Y., Nataliania Y.: Robust-learning fuzzy c-means clustering algorithm with unknown number of clusters. Pattern Recognition 2017, 71, pp. 45-59.

25. Molland A.F.: The Maritime Engineering Reference Book, A Guide to Ship Design, Construction and Operation, Butterworth-Heinemann Oct. 13, 2011.

26. Muślewski Ł.: Evaluation Method of Transport Systems Operation Quality. Polish Journal of Environmental Studies, Vol. 18, No. 2A, Hard Olsztyn 2009.

27. Muślewski Ł., Pająk M., Grządziela A., Musiał J.: Analysis of vibration time histories in the time domain for propulsion systems of minesweepers. Journal of Vibroengineering, 2015 Issue 3, Volume 17, pp. 1309-1316.

28. Muślewski Ł., Pająk M., Landowski B., Żółtowski B.: A method for determining the usability potential of ship steam boilers. Polish Maritime Research 4(92) 2016 Vol. 23, pp. 105-112.

29. Pająk M.: The space of a feature of a complex technical system. Scientific Problems of Machines Operation and Maintenance, 2/2010, ITeE Radom 2010, pp. 31-41. 
30. Pająk M.: Types of the states space of complex technical systems. Journal of KONES vol. 18 No. 3, Warsaw 2011, pp. 323-331.

31. Pająk M.: The technical states' space in the modelling process of operation tasks of a complex technical system. Maintenance Problems, 1/2014, ITeE Radom 2014, pp. 15-33.

32. Pająk M.: Operation and service processes expressed in the technical states space of a system. Maintenance Problems, 1/2016, ITeE Radom 2016, pp. 65-81.

33. Pająk M.: Identification of the operating parameters of a complex technical system important from the operational potential point of view. Institution of Mechanical Engineers Part I: Journal of Systems and Control Engineering, 2018 Issue 1, Volume 232 pp. 62-78.

34. Peng Wang, Taiyong Wang: Energy weighting method and its application to fault diagnosis of rolling bearing. Journal of Vibroengineering 2017, Vol. 19, Issue 1, pp. 223-236.

35. Piegat A.: Fuzzy modelling and control. EXIT, Warszawa 1999.

36. Rafiee J., Tse P.W., Harifi A., et al.: A novel technique for selecting mother wavelet function using an intelligent fault diagnosis system. Expert Systems with Applications 2009, 36, pp. 4862-4875.

37. Qiu H., Lee J., Lin J., et al.: Wavelet filter-based weak signature detection method and its application on rolling element bearing prognostics. Journal of Sound and Vibration, 2006 (289), pp. $1066-1090$.

38. Ruqiang Yan R., Gao R.X., Chen X.: Wavelets for fault diagnosis of rotary machines: A review with applications. Signal Processing, 2014 (96), pp. 1-15.

39. Saidi L., Ali J. B., Bechhoefer E., Benbouzid M.: Wind turbine high-speed shaft bearings health prognosis through a spectral Kurtosis-derived indices and SVR. Applied Acoustics 2017, Vol. 120, pp. 1-8.

40. Shih M., Doctor F., Fan S., Jen K., Shieh J.: Instantaneous 3D EEG Signal Analysis Based on Empirical Mode Decomposition and the Hilbert-Huang Transform Applied to Depth of Anaesthesia. Entropy 2015, Vol. 17, Issue 3, pp. 928-949.

41. Stefański T.: Steering Theory. Discrete Systems, Nonlinear Stochastic Processes, Static and Dynamic Optimization. Kielce University of Technology, Tom II, Kielce 2001.

42. Szabatin J.: Basics of Theory of Signals. WKŁ, Warszawa 2007.

43. Taria L., Barala Ch., Kimab S.: Fuzzy c-means clustering with prior biological knowledge. Journal of Biomedical Informatics 2009, Volume 42, Issue 1, pp. 74-81.

44. Wang H.C., Chen J., Dong G.M.: Feature extraction of rolling bearing's early weak fault based on EEMD and tuneable Q-factor wavelet transform. Mechanical Systems and Signal Processing 2014, Vol. 48, pp. 103-119.

45. Wang T.Y., Chu F.L., Han Q.K., Kong Y.: Compound faults detection in gearbox via meshing resonance and spectral kurtosis methods. Journal of Sound and Vibration 2017, Vol. 392, pp. 367-381.

46. Wang Y.X., Xiang J.W., Markert R., Liang M.: Spectral kurtosis for fault detection, diagnosis and prognostics of rotating machines: A review with applications. Mechanical Systems and Signal Processing 2016, Vol. 66-67, pp. 679-698.

47. Woropay M., Landowski B., Neubauer A.: Controlling reliability in the transport systems. B.P.E.-WIEM, BydgoszczRadom 2004.

48. Woropay M., Muślewski Ł.: Quality in a systemic approach. ITeE, Radom 2005.

49. Wu G. W., Wang C. M., Bao J. D., et al.: A wavelet threshold de-noising algorithm based on adaptive threshold function. Journal of Electronics \& Information Technology 2014, Vol. 36, Issue 6, pp. 1340-1347.

50. Xiaoming Xue, Jianzhong Zhou, Yanhe Xu, Wenlong Zhu, Chaoshun Li: An adaptively fast ensemble empirical mode decomposition method and its applications to rolling element bearing fault diagnosis. Mechanical Systems and Signal Processing 2015, 62-63, pp. 444-459.

51. Xiaoyun Gong, Wenliao Du, Anthimos Georgiadis, Baowei Zhao: Identification of multi-faults in rotor-bearing system using spectral kurtosis and EEMD. Journal of Vibroengineering 2017, Vol. 19 Issue 7, pp. 5036-5046.

52. Xi-hui Chen, Gang Cheng, Xian-lei Shan, Xiao Hu, Qiang Guo, Hou-guang Liu: Research of weak fault feature information extraction of planetary gear based on ensemble empirical mode decomposition and adaptive stochastic resonance. Measurement 2015, 73, pp. 55-67.

53. Yu Fajun, Fan Fuling, Wang Shuanghong, Zhou Fengxing: Transform-domain sparse representation based classification for machinery vibration signals. Journal of Vibroengineering 2018, Vol. 20, Issue 2, pp. 979-987.

54. Zerroukia A.A., Aifac T., Baddaria, K.: Prediction of natural fracture porosity from well log data by means of fuzzy ranking and an artificial neural network in Hassi Messaoud oil field Algeria. Journal of Petroleum Science and Engineering 2014, 115 , pp. $78-89$.

55. Zhang L. L., Zeng R.L., Jia J.D., et al.: Engine fault diagnosis based on work-cycle order tracking spectrum and fuzzy c-mean clustering. Automotive Engineering 2014, Vol. 36, Issue 8, pp. 1024-1028. 
56. Zhang D.C., Yu D.J.: Multi-fault diagnosis of gearbox based on resonance-based signal sparse decomposition and comb filter. Measurement 2017, Vol. 103, pp. 361-369.

57. Zhao M., Lin J., Wang X., et al.: A tacho-less order tracking technique for large speed variations. Mechanical Systems \& Signal Processing 2013, Issue 1, pp. 76-90.

58. Zhiquan Qi, Yingjie Tian, Yong Shi: Robust twin support vector machine for pattern classification. Pattern Recognition 2013, 46, pp. 305-316.

59. Zieliński T.P.: Digital Processing of Signals. From theory to practice. WKŁ, Warszawa 2009.

\section{CONTACT WITH THE AUTHORS}

Michał Pająk

e-mail:m.pajak@uthrad.pl

University of Technology and Humanities Stasieckiego 54

26-600 Radom

Poland

Łukasz Muślewski

e-mail:l.muslewski@wp.pl

University of Science and Technology

Kaliskiego 7

85-796 Bydgoszcz

Poland

Bogdan Landowski

e-mail:bogdan.landowski@utp.edu.pl

University of Science and Technology

Kaliskiego 7

85-796 Bydgoszcz

Poland

Andrzej Grządziela

e-mail: A.Grzadziela@amw.gdynia.pl

Polish Naval Academy

Śmidowicza 69

81-103 Gdynia

Poland 